\title{
Robustness analysis of elastoplastic structure subjected to double impulse
}

$\operatorname{AUTHOR}(S)$ :

Kanno, Yoshihiro; Takewaki, Izuru

\section{CITATION:}

Kanno, Yoshihiro ... [et al]. Robustness analysis of elasto plastic structure subjected to double impulse. Journal of Sound and Vibration 2016, 383: 309-323

\section{ISSUE DATE:}

2016-11-24

URL:

http://hdl.handle.net/2433/252319

\section{RIGHT:}

(c) 2016. This manuscript version is made available under the CC-BY-NC-ND 4.0 license

http://creativecommons.org/licenses/by-nc-nd/4.0/; The full-text file will be made open to the public on 24 November 2018 in accordance with publisher's 'Terms and Conditions for Self-Archiving'; この論文は出版社版でありません。引用 の際には出版社版をご確認ご利用ください。; This is not the published version. Please cite only the published version. 


\title{
Robustness Analysis of Elastoplastic Structure Subjected to Double Impulse
}

\author{
Yoshihiro Kanno ${ }^{\mathrm{a}, *}$, Izuru Takewaki ${ }^{\mathrm{b}}$ \\ ${ }^{a}$ Laboratory for Future Interdisciplinary Research of Science and Technology, Institute of Innovative \\ Research, Tokyo Institute of Technology, Nagatsuta 4259, Yokohama 226-8503, Japan. \\ ${ }^{b}$ Department of Architecture and Architectural Engineering, Graduate School of Engineering, Kyoto \\ University, Kyotodaigaku-Katsura, Nishikyo, Kyoto 615-8540, Japan.
}

\begin{abstract}
The double impulse has extensively been used to evaluate the critical response of an elastoplastic structure against a pulse-type input, including near-fault earthquake ground motions. In this paper, we propose a robustness assessment method for elastoplastic single-degree-of-freedom structures subjected to the double impulse input. Uncertainties in the initial velocity of the input, as well as the natural frequency and the strength of the structure, are considered. As fundamental properties of the structural robustness, we show monotonicity of the robustness measure with respect to the natural frequency. In contrast, we show that robustness is not necessarily improved even if the structural strength is increased. Moreover, the robustness preference between two structures with different values of structural strength can possibly reverse when the performance requirement is changed.
\end{abstract}

Keywords: Impulse; elastoplastic response; info-gap model; near-fault ground motion; robustness; uncertainty.

\section{Introduction}

It is often that a near-fault earthquake ground motion is modeled as a one-cycle sinusoidal wave [1-3]. Kalkan and Kunnath [1] showed that structural response against a certain type of near-fault ground motion is well simulated by using the one-cycle sinusoidal wave. To evaluate the critical response of a single-degree-of-freedom (SDOF) elastoplastic structure subjected to the near-fault ground motion, Kojima and Takewaki [4] proposed to use the double impulse input as a substitute of the corresponding onecycle sinusoidal wave. As observed in [5], an actually recorded pulse-type ground motion can be well approximated by one-cycle sinusoidal input and the corresponding double impulse. Figure 1 verifies this assertion for two representative recorded pulse-type ground motions [5]; see Kojima and Takewaki [6] for further verification. It is also known that

\footnotetext{
*Corresponding author

Email addresses: kanno.y.af@m.titech.ac.jp (Yoshihiro Kanno), takewaki@archi.kyoto-u.ac.jp (Izuru Takewaki) 
the double impulse can be used to derive the dynamic stability criterion for elastoplastic structures [6] and to simulate the rocking vibration overturning of a rigid block [7] under near-fault ground motions. The approach in [4] has been extended to the triple impulse [8], considered as a substitute of the forward-directivity near-fault ground motion, and the multiple impulse [9], considered as a substitute of the long-duration earthquake ground motion. Not only for ground motions, but also for generic impulse-like inputs, it is often that a half- or one-cycle sinusoidal wave is used as a fairly good approximation $[10,11]$. In this paper, we consider the elastoplastic response of a structure subjected to the double impulse input. Besides providing us with good approximation for structural response under the near-fault ground motion, using the double impulse has advantages. Particularly, we can derive a closed-form solution of the critical elastoplastic response of an SDOF structure [4]. The closed-form solution enables us to investigate insights of the critical elastoplastic response in dynamics $[6,7]$. In this paper, we make use of this closed-form solution to assess structural robustness. Due to the presence of the closedform solution, the analysis presented in this paper does not resort to any approximation, such as the sensitivity analysis and the Taylor expansion, of the structural response.

The critical response of an SDOF elastoplastic structure subjected to double impulse depends on the initial velocity of the input (i.e., the input level), the yield deformation of the structure, and the undamped natural frequency of the structure [4]. In this paper, we assume that these three parameters are known only imprecisely (or uncertain), and propose a method for quantitatively evaluating the structural robustness against the uncertainty. As a quantitative measure of robustness, we adopt the robustness function, defined within the framework of the info-gap theory [12]. The robustness function has been used extensively to evaluate the robustness of engineering structures in diverse situations [13-20].

The following papers that deal with uncertainties in dynamic response of inelastic structures have relevance to our present work. Au [21] formulated an optimization problem to find the critical excitation, parameterized in the time domain, for an SDOF elastoplastic structure and solved the problem numerically. In the framework of reliability analysis, $\mathrm{Au}[22,23]$ and $\mathrm{Au}$ et al. [24] proposed estimation methods for the first passage probability of an elastoplastic structure subjected to white noise excitation. Moustafa et al. [25] considered the critical earthquake loads modeled by combination of waves with certain frequency band and time interval. Similarly, Abbas [26] proposed a critical earthquake load model for inelastic structures by using a Fourier series modulated by an envelope function. Kanno and Takewaki [27] proposed an optimization-based method for predicting a confidential bound for the dynamic steady-state responses of a damped structure subjected to uncertain driving loads.

The paper is organized as follows. Section 2 provides an overview of the necessary background. Section 3 presents some fundamental properties of the elastoplastic response of a structure subjected to the critical double impulse input. In sections 4,5 , and 6 , we study a quantitative measure of robustness of structures when the initial velocity of the ground motion, the natural frequency of the structure, or the structural strength is assumed to be uncertain. In section 7 , we show some fundamental properties of the structural robustness. Some conclusions are drawn in section 8 .

A few words regarding notation. For $a, b \in \mathbb{R}$ with $a<b$, we denote by $[a, b]$ and $(a, b)$ the closed and open intervals between $a$ and $b$, respectively, i.e., $[a, b]=\{x \in \mathbb{R} \mid$ $a \leq x \leq b\}$ and $(a, b)=\{x \in \mathbb{R} \mid a<x<b\}$. 


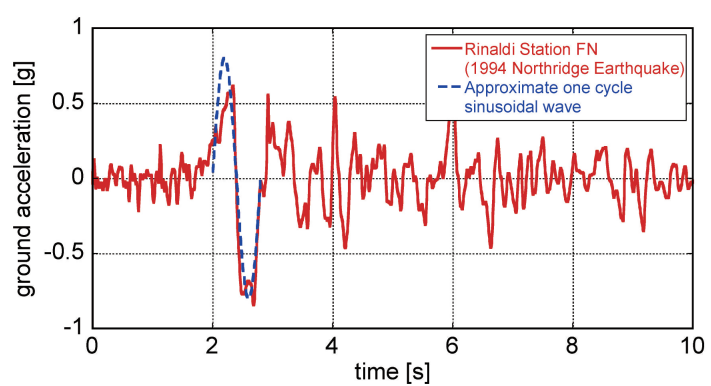

(a)

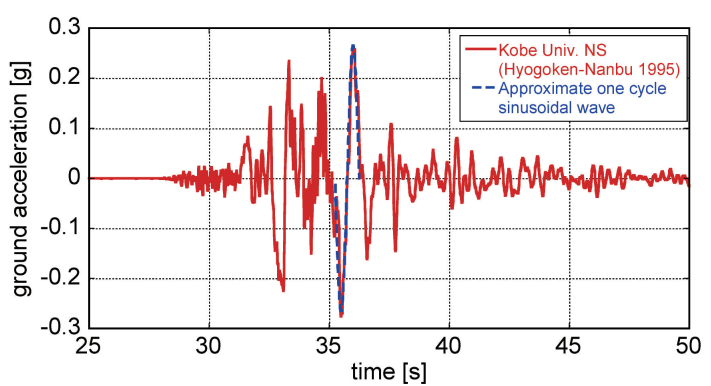

(b)

Figure 1: Modeling of part of pulse-type recorded ground motion into the corresponding one-cycle sinusoidal input [5]. (a) Rinaldi station fault normal component during the Northridge earthquake in 1994; and (b) Kobe University NS component (almost fault-normal) during the Hyogoken-Nanbu (Kobe) earthquake in 1995 .

\section{Preliminary results}

In this section, we briefly review the existing results on the critical elastoplastic response against the double impulse input and a quantitative measure of robustness defined within the framework of the info-gap theory.

\subsection{Maximum elastoplastic deformation against double impulse input}

Following [4], we assume that the input acceleration is modeled as the double impulse. Let $v$ denote the initial velocity of the input. We use $t_{0}$ to denote the time interval between the two impulses. The input acceleration is characterized by $v$ and $t_{0}$.

Consider an undamped elastic-perfectly plastic SDOF system. Let $d_{\mathrm{y}}$ and $\omega$ denote the yield deformation and the (undamped) natural circular frequency, respectively. Define $V_{\mathrm{y}}$ by

$$
V_{\mathrm{y}}=\omega d_{\mathrm{y}},
$$

where $V_{\mathrm{y}}$ indicates the velocity of the impulse such that the structure just attains the yield deformation after the first impulse.

We choose $t_{0}$ so that the deformation of the structure attains the maximum value under a constant velocity $v$ [4]. Then the pair of $t_{0}$ and $v$ defines the critical double impulse input for the elastoplastic SDOF structure. The corresponding deformation, called the critical response, provides us with a (tight) upper bound for the structural response [25, 28-30]. Let $u_{\max }^{(1)}$ denote the maximum (absolute value of) deformation after the first impulse (and before the second impulse). We use $u_{\max }^{(2)}$ to denote the maximum (absolute value of) deformation after the second impulse. Figure 2 explains the problem setting and the definitions of $u_{\max }^{(1)}$ and $u_{\max }^{(2)}$. An SDOF elastic-perfectly plastic structure is subjected to the double impulse input, as shown at the top of Figure 2. After the first impulse, the structure undergoes free vibration, until the second impulse is given. Point " 2 " in the schematic diagram of Figure 2 corresponds to $u_{\max }^{(1)}$, which can be computed explicitly by making use of the energy balance law. The time interval, $t_{0}$, is then chosen so that the deformation after the second impulse is maximized. Point " 4 " 

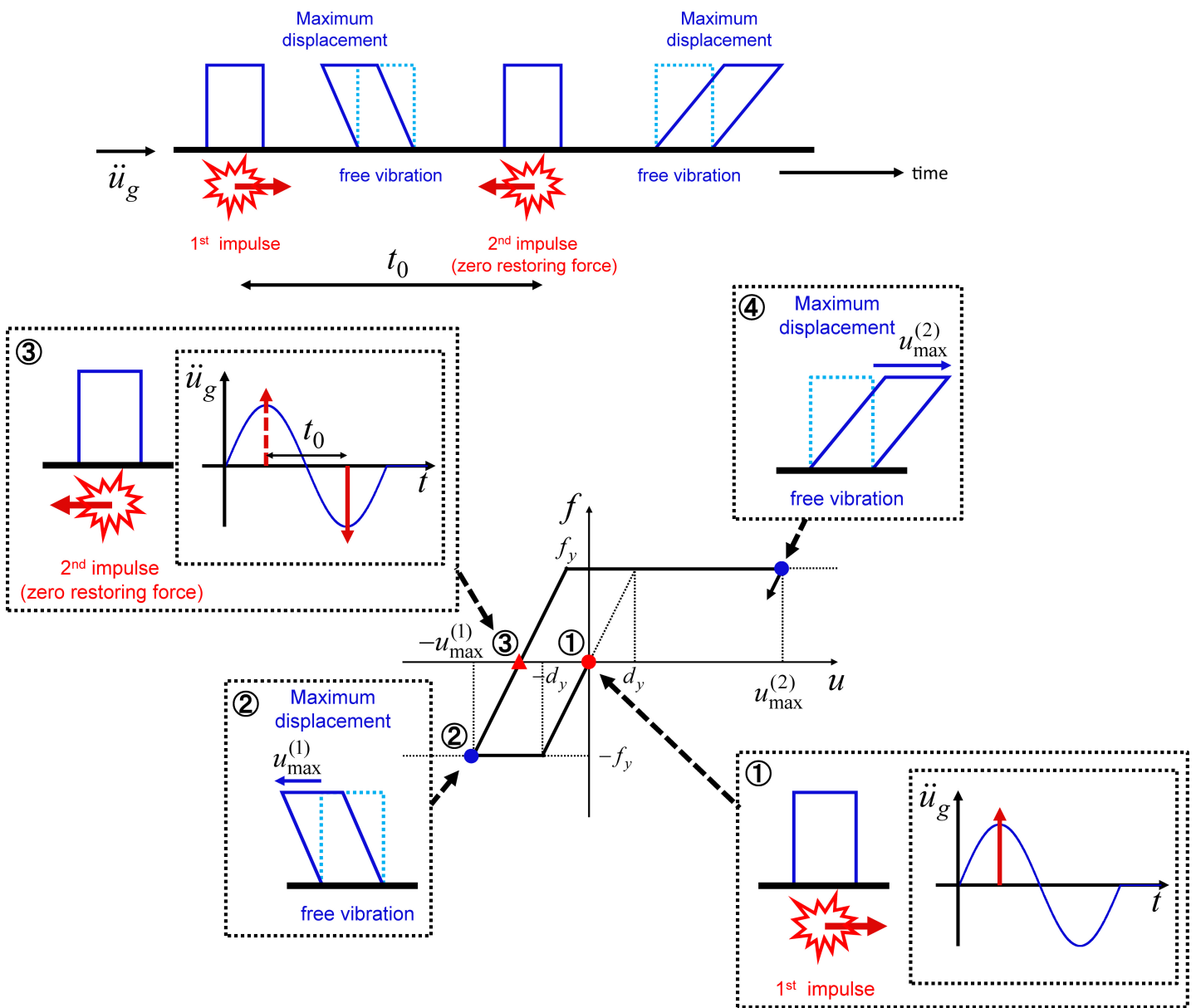

Figure 2: A schematic representation of the critical double impulse and the maximum structural deformation.

in the schematic diagram of Figure 2 corresponds to $u_{\max }^{(2)}$, which can also be computed explicitly from the energy balance law. The total maximum deformation of the structure is therefore the larger one among $u_{\max }^{(1)}$ and $u_{\max }^{(2)}$.

It is shown in [4] that $u_{\max }^{(1)}$ is written in terms of $v, d_{\mathrm{y}}$ and $V_{\mathrm{y}}$ as

$$
u_{\max }^{(1)}= \begin{cases}\frac{d_{\mathrm{y}}}{V_{\mathrm{y}}} v & \text { if } 0<v \leq V_{\mathrm{y}}, \\ \frac{1}{2} \frac{d_{\mathrm{y}}}{V_{\mathrm{y}}^{2}} v^{2}+\frac{1}{2} d_{\mathrm{y}} & \text { if } v \geq V_{\mathrm{y}},\end{cases}
$$


and $u_{\max }^{(2)}$ is written as

$$
u_{\mathrm{max}}^{(2)}= \begin{cases}2 \frac{d_{\mathrm{y}}}{V_{\mathrm{y}}} v & \text { if } 0<v<\frac{1}{2} V_{\mathrm{y}}, \\ 2 \frac{d_{\mathrm{y}}}{V_{\mathrm{y}}^{2}} v^{2}+\frac{1}{2} d_{\mathrm{y}} & \text { if } \frac{1}{2} V_{\mathrm{y}} \leq v<V_{\mathrm{y}}, \\ \frac{d_{\mathrm{y}}}{V_{\mathrm{y}}} v+\frac{3}{2} d_{\mathrm{y}} & \text { if } v \geq V_{\mathrm{y}} .\end{cases}
$$

It is worth noting that the condition $v \geq V_{\mathrm{y}}$ in (2) and (3) implies that the structure undergoes plastic deformation before the second impulse input. Therefore, the maximum value of the deformation, denoted $\mu$, is given by

$$
\begin{aligned}
\mu:=\max \left\{u_{\max }^{(1)}, u_{\max }^{(2)}\right\} & \begin{array}{ll}
2 \frac{d_{\mathrm{y}}}{V_{\mathrm{y}}} v & \text { if } 0<v<\frac{1}{2} V_{\mathrm{y}}, \\
2 \frac{d_{\mathrm{y}}}{V_{\mathrm{y}}^{2}} v^{2}+\frac{1}{2} d_{\mathrm{y}} & \text { if } \frac{1}{2} V_{\mathrm{y}} \leq v<V_{\mathrm{y}}, \\
\frac{d_{\mathrm{y}}}{V_{\mathrm{y}}} v+\frac{3}{2} d_{\mathrm{y}} & \text { if } V_{\mathrm{y}} \leq v<(\sqrt{3}+1) V_{\mathrm{y}}, \\
\frac{1}{2} \frac{d_{\mathrm{y}}}{V_{\mathrm{y}}^{2}} v^{2}+\frac{1}{2} d_{\mathrm{y}} & \text { if } v \geq(\sqrt{3}+1) V_{\mathrm{y}} .
\end{array}
\end{aligned}
$$

\subsection{Info-gap uncertainty and robustness}

In the info-gap theory [12], the robustness function serves as a quantitative measure of a system, uncertainty of which is described by an info-gap model. Following [12], this section summarizes the notion of robustness function.

Let $p$ denote a system parameter that possesses uncertainty. In sections $4-7, p$ concretely means $v, \omega$, or $d_{\mathrm{y}}$. The uncertainty of $p$ is represented by an info-gap uncertainty model as $p \in \mathcal{U}(\alpha, \tilde{p})$, where $\tilde{p}$ is the nominal value of $p$ and $\alpha \geq 0$ is a parameter representing the magnitude of the uncertainty. Any info-gap model should have the following two properties:

- Nesting: $\alpha<\alpha^{\prime}$ implies $\mathcal{U}(\alpha, \tilde{p}) \subseteq \mathcal{U}\left(\alpha^{\prime}, \tilde{p}\right)$;

- Contraction: $\mathcal{U}(0, \tilde{p})=\{\tilde{p}\}$.

Suppose that performance (e.g., the maximum deformation) of the system depends on $p$ and is denoted by $g(p)$. The performance requirement is that $g(p)$ does not exceed the maximal allowable value, $g^{\text {c }}$, i.e.,

$$
g(p) \leq g^{\mathrm{c}}
$$

The robustness function, denoted $\hat{\alpha}$, is defined as the maximum value of $\alpha$ with which the performance requirement, (5), is always satisfied, i.e.,

$$
\hat{\alpha}\left(\tilde{p}, g^{\mathrm{c}}\right)=\max \left\{\alpha \mid \max \{g(p) \mid p \in \mathcal{U}(\alpha ; \tilde{p})\} \leq g^{\mathrm{c}}\right\} .
$$


We define $\hat{\alpha}\left(\tilde{p}, g^{\mathrm{c}}\right)=0$ if $g(\tilde{p})<g^{\mathrm{c}}$. By definition, any element of $\mathcal{U}\left(\hat{\alpha}\left(\tilde{p}, g^{\mathrm{c}}\right), \tilde{p}\right)$ satisfies the performance requirement, (5). Therefore, if follows from the nesting property of the info-gap model that the greater value of the robustness function means larger robustness.

Robustness assessment methods for engineering structures based on the info-gap theory can be found in, e.g., [13-20].

\section{Monotonicity of maximum deformation}

In this section, we investigate a few fundamental properties of the maximum deformation caused by double impulse.

Recall that the maximum deformation is given by (4), where $v, \omega, d_{\mathrm{y}}>0$. By substituting (1) into (4), we can eliminate $V_{\mathrm{y}}$ as

$$
\mu\left(v, \omega, d_{\mathrm{y}}\right)= \begin{cases}2 \frac{v}{\omega} & \text { if } 0<\frac{v}{\omega}<\frac{1}{2} d_{\mathrm{y}} \\ 2 \frac{1}{d_{\mathrm{y}}}\left(\frac{v}{\omega}\right)^{2}+\frac{1}{2} d_{\mathrm{y}} & \text { if } \frac{1}{2} d_{\mathrm{y}} \leq \frac{v}{\omega}<d_{\mathrm{y}} \\ \frac{v}{\omega}+\frac{3}{2} d_{\mathrm{y}} & \text { if } d_{\mathrm{y}} \leq \frac{v}{\omega}<(\sqrt{3}+1) d_{\mathrm{y}} \\ \frac{1}{2 d_{\mathrm{y}}}\left(\frac{v}{\omega}\right)^{2}+\frac{1}{2} d_{\mathrm{y}} & \text { if } \frac{v}{\omega} \geq(\sqrt{3}+1) d_{\mathrm{y}} .\end{cases}
$$

It is clear from (7) that $\mu$ is a piecewise-quadratic function of $v / \omega .^{1}$ The following observation is useful for the discussions presented later.

Proposition 1. The function $\mu$ has the following properties:

(i) For any $d_{\mathrm{y}}>0,0<v / \omega<v^{\prime} / \omega^{\prime}$ implies $\mu\left(v, \omega, d_{\mathrm{y}}\right)<\mu\left(v^{\prime}, \omega^{\prime}, d_{\mathrm{y}}\right)$.

(ii) For any $\omega>0$ and $d_{\mathrm{y}}>0, \mu\left(v, \omega, d_{\mathrm{y}}\right)$ is strictly monotonically increasing with respect to $v$.

(iii) For any $v>0$ and $d_{\mathrm{y}}>0, \mu\left(v, \omega, d_{\mathrm{y}}\right)$ is strictly monotonically decreasing with respect to $\omega$.

Proof. Assertion (i) follows from the fact that the coefficients of $v / \omega$ and $(v / \omega)^{2}$ are all positive. Assertions (ii) and (iii) are immediate consequences of (i).

Proposition 1 (ii) and (iii) play fundamental roles in studying the robustness functions in sections 4 and 5 , respectively.

\footnotetext{
${ }^{1}$ It should be clear that piecewise-linear functions are included as a special class of piecewise-quadratic functions.
} 


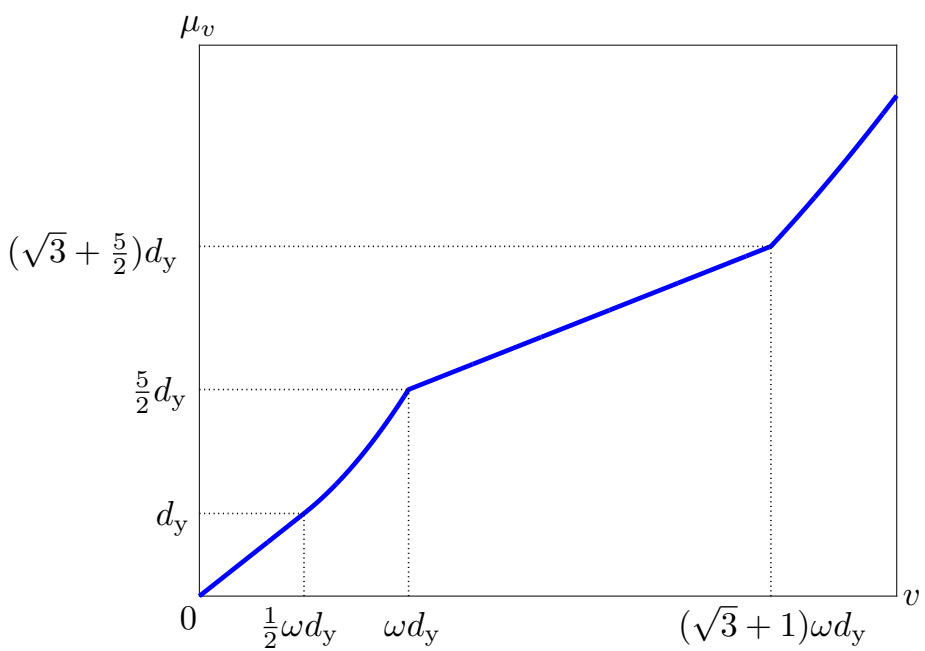

Figure 3: The graph of $\mu_{v}$.

\section{Uncertainty in initial velocity}

In this section, we assume that $\omega$ and $d_{\mathrm{y}}$ are fixed (or known precisely) and only $v$ is uncertain. In this view, we consider $\mu$ in (7) as a function of $v$ and write it as $\mu_{v}\left(v ; \omega, d_{\mathrm{y}}\right)$. Dependence of $\mu$ on $v$ is clearly seen by rewriting (7) as

$$
\mu_{v}\left(v ; \omega, d_{\mathrm{y}}\right)= \begin{cases}2 \frac{1}{\omega} v & \text { if } v \in\left(0, \frac{1}{2} \omega d_{\mathrm{y}}\right), \\ 2 \frac{1}{\omega^{2} d_{\mathrm{y}}} v^{2}+\frac{1}{2} d_{\mathrm{y}} & \text { if } v \in\left[\frac{1}{2} \omega d_{\mathrm{y}}, \omega d_{\mathrm{y}}\right), \\ \frac{1}{\omega} v+\frac{3}{2} d_{\mathrm{y}} & \text { if } v \in\left[\omega d_{\mathrm{y}},(\sqrt{3}+1) \omega d_{\mathrm{y}}\right), \\ \frac{1}{2} \frac{1}{\omega^{2} d_{\mathrm{y}}} v^{2}+\frac{1}{2} d_{\mathrm{y}} & \text { if } v \in\left[(\sqrt{3}+1) \omega d_{\mathrm{y}},+\infty\right) .\end{cases}
$$

For notational simplicity, we often write $\mu_{v}(v)$ instead of $\mu_{v}\left(v ; \omega, d_{\mathrm{y}}\right)$. Figure 3 shows the graph of $\mu_{v}$.

The uncertainty in $v$ is described by using an info-gap model introduced in section 2.2 . Let $\tilde{v}$ denote the nominal value (or the best estimate) of $v$. Assume that $v$ can take any value in the set

$$
\mathcal{V}(\alpha)=\{v \in \mathbb{R}|| v-\tilde{v} \mid \leq \alpha, v>0\},
$$

where $\alpha \geq 0$ is the parameter representing the level (or the magnitude) of uncertainty.

As for the performance requirement, $g^{\mathrm{c}}$ in section 2.2 , we consider the maximal allowable displacement, denoted $u^{\mathrm{c}}$. The robustness function depends on the performance requirement, $u^{\mathrm{c}}$, the nominal value of the input velocity, $\tilde{v}$, and the structural design, $\omega$ and $d_{\mathrm{y}}$. Hence, we use $\hat{\alpha}_{v}\left(u^{\mathrm{c}} ; \tilde{v}, \omega, d_{\mathrm{y}}\right)$ to denote the robustness function. For notational simplicity, we also write $\hat{\alpha}_{v}\left(u^{\mathrm{c}}\right)$. Following section 2.2 , the robustness function is defined 
by

$$
\hat{\alpha}_{v}\left(u^{\mathrm{c}} ; \tilde{v}, \omega, d_{\mathrm{y}}\right)=\max \left\{\alpha \mid \max \left\{\mu_{v}(v) \mid v \in \mathcal{V}(\alpha)\right\} \leq u^{\mathrm{c}}\right\}
$$

As shown in Proposition 1 (ii), $\mu_{v}$ is a strictly monotonically increasing function. Therefore, we obtain

$$
\max \left\{\mu_{v}(v) \mid v \in \mathcal{V}(\alpha)\right\}=\mu_{v}(\tilde{v}+\alpha) .
$$

Substitution of (11) into (10) yields

$$
\hat{\alpha}_{v}\left(u^{\mathrm{c}}\right)=\max \left\{\alpha \mid \mu_{v}(\tilde{v}+\alpha) \leq u^{\mathrm{c}}\right\} .
$$

Since the maximum in (12) is attained when the inequality constraint becomes active, the relation

$$
\mu_{v}\left(\tilde{v}+\hat{\alpha}_{v}\left(u^{\mathrm{c}}\right)\right)=u^{\mathrm{c}}
$$

holds. Consequently, the value of robustness function, $\hat{\alpha}_{v}\left(u^{\mathrm{c}}\right)$, can be determined from (13). More precisely, from (13) we obtain ${ }^{2}$

$$
\hat{\alpha}_{v}\left(u^{\mathrm{c}}\right)=\max \left\{\mu_{v}^{-1}\left(u^{\mathrm{c}}\right)-\tilde{v}, 0\right\},
$$

where $\mu_{v}^{-1}$ is the inverse function of $\mu_{v}$.

The graph showing the variation of $\hat{\alpha}_{v}$ as a function of $u^{\mathrm{c}}$ is called a robustness curve [12]. Roughly speaking, the graph of $\mu_{v}^{-1}$ in (14) is obtained by exchanging the horizontal axis and the vertical axis of the graph of $\mu_{v}$ in Figure 3, and then the robustness curve is obtained by applying parallel translation to the graph of $\mu_{v}^{-1}$ in the vertical direction.

Example 2. As for two different structural designs, consider case (A) and case (B) in Table 1. We suppose a low or middle-rise building. Both cases satisfy $\tilde{v} \in\left(\frac{1}{2} \omega d_{\mathrm{y}}, \omega d_{\mathrm{y}}\right)$. Figure 4 shows the robustness curves. It is observed that the two robustness curves are crossing twice. This has important design implications. In the nominal situation, case

Table 1: Definitions of cases (A)-(G).

\begin{tabular}{lrrr}
\hline Case & Circ. freq. (rad/s) & Yield def. (m) & Init. vel. $(\mathrm{m} / \mathrm{s})$ \\
\hline$(\mathrm{A})$ & $\omega=10.0$ & $d_{\mathrm{y}}=0.030$ & $\tilde{v}=0.225$ \\
$(\mathrm{~B})$ & $\omega=10.0$ & $d_{\mathrm{y}}=0.040$ & $\tilde{v}=0.225$ \\
$(\mathrm{C})$ & $\tilde{\omega}=8.0$ & $d_{\mathrm{y}}=0.030$ & $v=0.200$ \\
$(\mathrm{D})$ & $\tilde{\omega}=8.0$ & $d_{\mathrm{y}}=0.040$ & $v=0.200$ \\
$(\mathrm{E})$ & $\omega=10.0$ & $\tilde{d}_{\mathrm{y}}=0.009$ & $v=0.200$ \\
$(\mathrm{~F})$ & $\omega=10.0$ & $\tilde{d}_{\mathrm{y}}=0.015$ & $v=0.200$ \\
$(\mathrm{G})$ & $\omega=10.0$ & $\tilde{d}_{\mathrm{y}}=0.022$ & $v=0.200$ \\
\hline
\end{tabular}

\footnotetext{
${ }^{2}$ If $\hat{\alpha}_{v}\left(u^{\mathrm{c}}\right)$ satisfying $(13)$ is negative, then $\mu_{v}(\tilde{v})>u^{\mathrm{c}}$, i.e., the performance requirement is not
} satisfied even at the nominal value, $\tilde{v}$. In this case, it is defined that $\hat{\alpha}_{v}\left(u^{\mathrm{c}}\right)=0[12]$. 


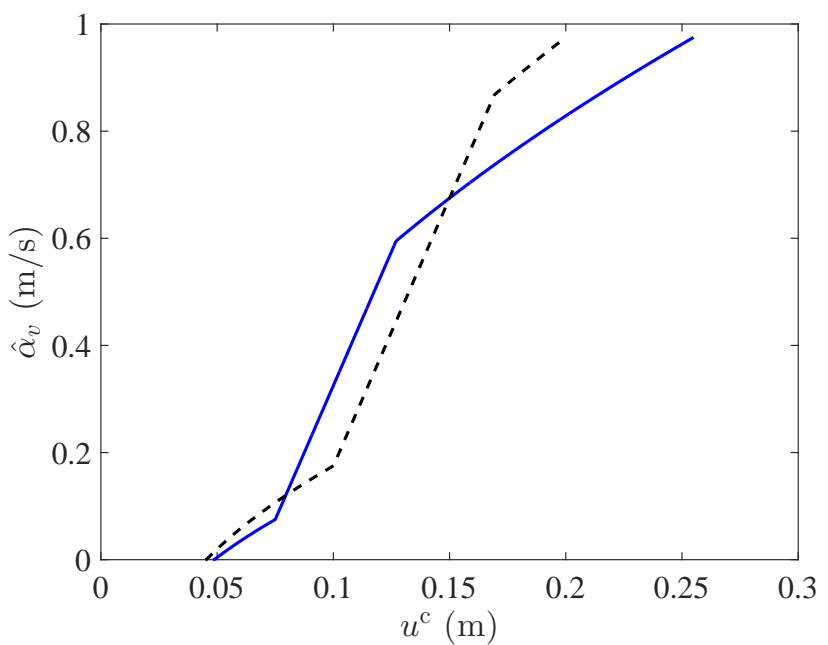

Figure 4: Robustness curves of two structures when uncertainty in the initial velocity is considered. "—_" Case (A); and "- --" case (B).

(B) is preferable to case (A). When the performance requirement, $u^{\mathrm{c}}$, is small, case (B) is still preferable since it has larger robustness. When $u^{\mathrm{c}}$ is increased, there exists an interval such that case (A) has larger robustness than case (B). For a higher range of $u^{\mathrm{c}}$, the robustness preferences are again reversed, i.e., case (B) is preferred over case (A). Thus the robustness-preference between these two designs changes as the maximal allowable deformation changes.

\section{Uncertainty in natural frequency}

In this section, we assume that $v$ and $d_{\mathrm{y}}$ are fixed and only $\omega$ is uncertain. In this view, we consider $\mu$ as a function of $\omega$ and write it as $\mu_{\omega}\left(\omega ; v, d_{\mathrm{y}}\right)$. It is worth noting that, since $\omega$ is proportional to the square root of stiffness of the structure, the uncertainty of $\omega$ under fixed $d_{\mathrm{y}}$ corresponds to the uncertainty of the stiffness and strength of the structure. To see the dependence of $\mu$ on $\omega$ clearly, it is convenient to rewrite (7) as

$$
\mu_{\omega}\left(\omega ; v, d_{\mathrm{y}}\right)= \begin{cases}\frac{1}{2} \frac{v^{2}}{d_{\mathrm{y}}} \frac{1}{\omega^{2}}+\frac{1}{2} d_{\mathrm{y}} & \text { if } \omega \in\left(0, \frac{\sqrt{3}-1}{2} \frac{v}{d_{\mathrm{y}}}\right], \\ \frac{1}{\omega}+\frac{3}{2} d_{\mathrm{y}} & \text { if } \omega \in\left(\frac{\sqrt{3}-1}{2} \frac{v}{d_{\mathrm{y}}}, \frac{v}{d_{\mathrm{y}}}\right], \\ 2 \frac{v^{2}}{d_{\mathrm{y}}} \frac{1}{\omega^{2}}+\frac{1}{2} d_{\mathrm{y}} & \text { if } \omega \in\left(\frac{v}{d_{\mathrm{y}}}, 2 \frac{v}{d_{\mathrm{y}}}\right], \\ 2 v \frac{1}{\omega} & \text { if } \omega \in\left(2 \frac{V}{d_{\mathrm{y}}},+\infty\right) .\end{cases}
$$

For notational simplicity, we often write $\mu_{\omega}(\omega)$ instead of $\mu_{\omega}\left(\omega ; v, d_{\mathrm{y}}\right)$. Figure 5 shows the graph of $\mu_{\omega}$. 


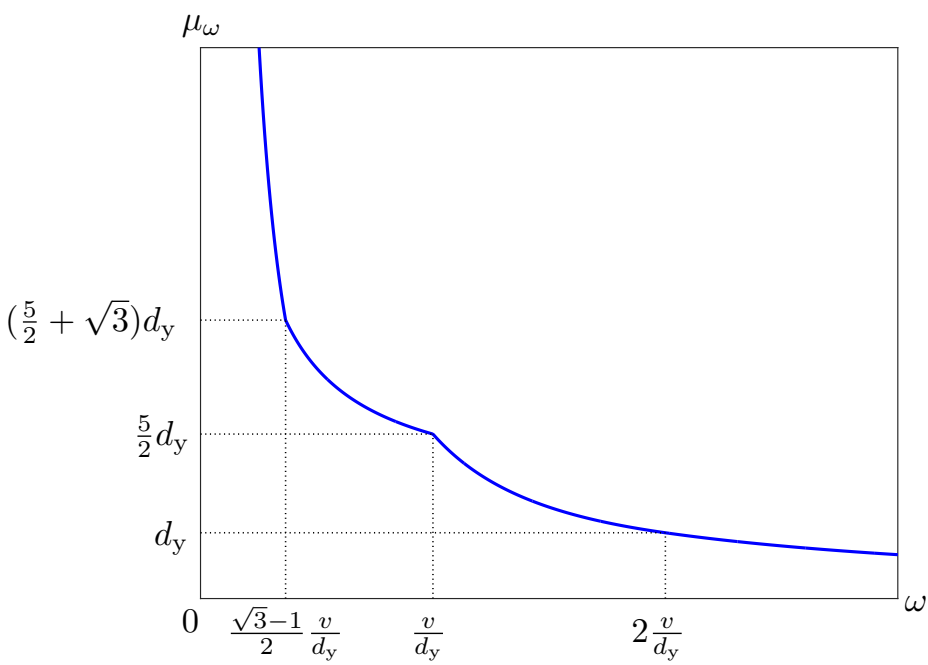

Figure 5: The graph of $\mu_{\omega}$.

Let $\tilde{\omega}$ denote the nominal value of $\omega$. Define the uncertainty set of $\omega$ by

$$
\Omega(\alpha)=\{\omega \in \mathbb{R}|| \omega-\tilde{\omega} \mid \leq \alpha, \omega>0\} .
$$

As in section 3 , the performance requirement is the maximal allowable deformation, $u^{\mathrm{c}}$. Then the robustness function is defined by

$$
\hat{\alpha}_{\omega}\left(u^{\mathrm{c}} ; v, \tilde{\omega}, d_{\mathrm{y}}\right)=\max \left\{\alpha \mid \max \left\{\mu_{\omega}(\omega) \mid \omega \in \Omega(\alpha)\right\} \leq u^{\mathrm{c}}\right\} .
$$

For notational simplicity, we often write $\hat{\alpha}_{\omega}\left(u^{\mathrm{c}}\right)$ instead of $\hat{\alpha}_{\omega}\left(u^{\mathrm{c}} ; v, \tilde{\omega}, d_{\mathrm{y}}\right)$.

As shown in Proposition 1 (iii), $\mu_{\omega}$ is a strictly monotonically decreasing function. Therefore, we obtain

$$
\max \left\{\mu_{\omega}(\omega) \mid \omega \in \Omega(\alpha)\right\}= \begin{cases}\mu_{\omega}(\tilde{\omega}-\alpha) & \text { if } \alpha<\tilde{\omega}, \\ +\infty & \text { otherwise, }\end{cases}
$$

where the fact that $\Omega=(0, \tilde{\omega}+\alpha]$ for $\alpha \geq \tilde{\omega}$ has been used. Substitution of (18) into (17) results in

$$
\hat{\alpha}_{\omega}\left(u^{\mathrm{c}}\right)=\max \left\{\alpha \mid \mu_{\omega}(\tilde{\omega}-\alpha) \leq u^{\mathrm{c}}\right\} .
$$

The maximum in (19) is attained when the inequality constraint becomes active. This yields

$$
\mu_{\omega}\left(\tilde{\omega}-\hat{\alpha}_{\omega}\left(u^{\mathrm{c}}\right)\right)=u^{\mathrm{c}} .
$$

The value of robustness function, $\hat{\alpha}_{\omega}\left(u^{\mathrm{c}}\right)$, can be determined from condition (20). More precisely, the robustness function is explicitly written as

$$
\hat{\alpha}_{\omega}\left(u^{\mathrm{c}}\right)=\max \left\{\tilde{\omega}-\mu_{\omega}^{-1}\left(u^{\mathrm{c}}\right), 0\right\},
$$

where $\mu_{\omega}^{-1}$ is the inverse function of $\mu_{\omega}$. 


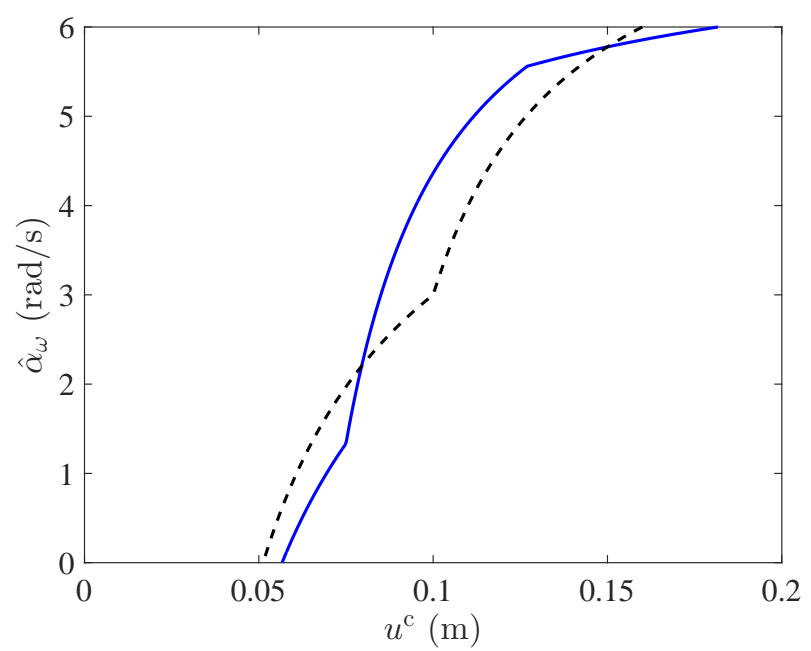

Figure 6: Robustness curves of two structures when uncertainty in the natural frequency is considered. "__ Case (C); and "- _." case (D).

Example 3. Consider cases (C) and (D) in Table 1. Both cases satisfy $\tilde{\omega} \in\left(v / d_{\mathrm{y}}, 2 v / d_{\mathrm{y}}\right)$. Figure 6 shows variation of $\hat{\alpha}_{\omega}$ with respect to $u^{\mathrm{c}}$. It is observed that the two curves are crossing twice. Namely, the robustness-preference between these two designs changes as the maximal allowable deformation changes.

Remark 4. Suppose that both the initial velocity of the input, $v$, and the natural circular frequency of the structure, $\omega$, are uncertain. Moreover, suppose that the magnitude of the uncertainty is known. Then it is easy to check if, in the worst-case scenario, the structure satisfies the performance requirement or not. More concretely, suppose that $d_{\mathrm{y}}$ is fixed and the uncertainty model of $v$ and $\omega$ is given as

$$
v \in \mathcal{V}(\alpha), \quad \omega \in \Omega(\beta),
$$

where $\alpha>0$ and $\beta>0$ are constants. Then, from Proposition 1 (i) we see that

$$
\max \left\{\mu\left(v, \omega, d_{\mathrm{y}}\right) \mid v \in \mathcal{V}(\omega), \omega \in \Omega(\beta)\right\}= \begin{cases}\mu\left(\tilde{v}+\alpha, \tilde{\omega}-\beta, d_{\mathrm{y}}\right) & \text { if } \tilde{\omega}>\beta, \\ +\infty & \text { otherwise }\end{cases}
$$

holds. Thus, the maximum deformation can be obtained explicitly, even if both $v$ and $\omega$ are assumed to be uncertain.

\section{Uncertainty in yield deformation}

In this section, we assume that $v$ and $\omega$ are fixed (or known precisely) and only $d_{\mathrm{y}}$ is uncertain. Hence, we consider $\mu$ as a function of $d_{\mathrm{y}}$ and write it as $\mu_{\omega}\left(d_{\mathrm{y}} ; v, \omega\right)$. Since $d_{\mathrm{y}}$ is proportional to the yield strength of the structure under fixed $\omega$ (or the fixed stiffness), the uncertainty of $d_{\mathrm{y}}$ under fixed $\omega$ corresponds to the uncertainty of yield strength. To 


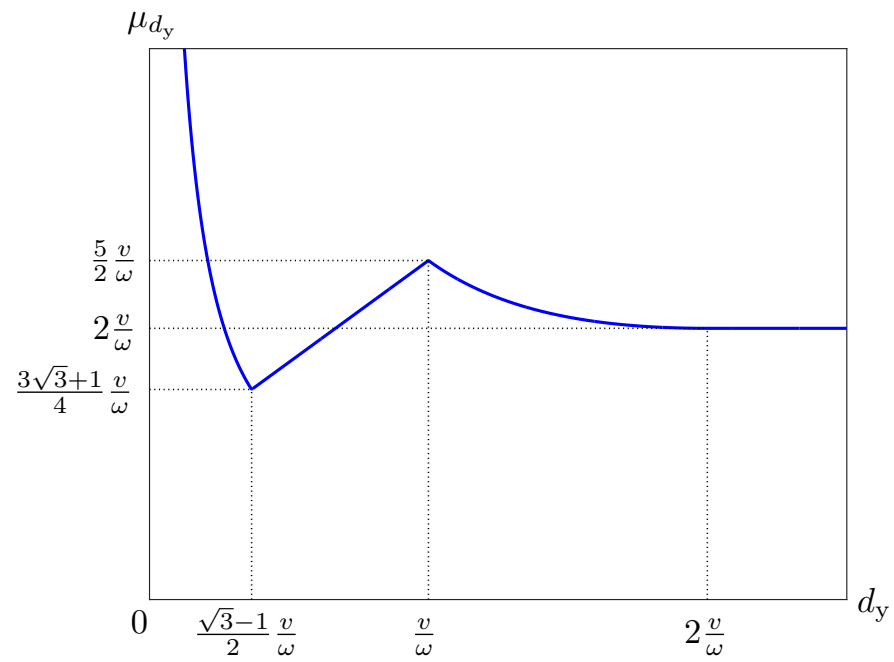

Figure 7: The graph of $\mu_{d_{y}}$.

see the dependence of $\mu$ on $d_{\mathrm{y}}$ clearly, it is convenient to rewrite (7) as

$$
\mu_{d_{\mathrm{y}}}\left(d_{\mathrm{y}} ; v, \omega\right)= \begin{cases}\frac{1}{2} d_{\mathrm{y}}+\frac{1}{2} \frac{v^{2}}{\omega^{2}} \frac{1}{d_{\mathrm{y}}} & \text { if } d_{\mathrm{y}} \in\left(0, \frac{\sqrt{3}-1}{2} \frac{v}{\omega}\right], \\ \frac{3}{2} d_{\mathrm{y}}+\frac{v}{\omega} & \text { if } d_{\mathrm{y}} \in\left(\frac{\sqrt{3}-1}{2} \frac{v}{\omega}, \frac{v}{\omega}\right], \\ \frac{1}{2} d_{\mathrm{y}}+2 \frac{v^{2}}{\omega^{2}} \frac{1}{d_{\mathrm{y}}} & \text { if } d_{\mathrm{y}} \in\left(\frac{v}{\omega}, 2 \frac{v}{\omega}\right], \\ 2 \frac{v}{\omega} & \text { if } d_{\mathrm{y}} \in\left(2 \frac{v}{\omega},+\infty\right) .\end{cases}
$$

For notational simplicity, we often write $\mu_{d_{\mathrm{y}}}\left(d_{\mathrm{y}}\right)$ instead of $\mu_{d_{\mathrm{y}}}\left(d_{\mathrm{y}} ; v, \omega\right)$. Figure 7 shows the graph of $\mu_{d_{\mathrm{y}}}$.

Prior to study of the robustness function, we investigate some properties of $\mu_{d_{y}}$. For notational simplicity, define $\bar{d}_{1}, \bar{d}_{2}$, and $\bar{d}_{3}$ by

$$
\bar{d}_{1}=\frac{\sqrt{3}-1}{2} \frac{v}{\omega}, \quad \bar{d}_{2}=\frac{v}{\omega}, \quad \bar{d}_{3}=2 \frac{v}{\omega} .
$$

It is an easy matter to see that $\mu_{d_{y}}$ has the following properties:

- $\mu_{d_{y}}\left(d_{\mathrm{y}}\right)$ attains the (global) minimum at $d_{\mathrm{y}}=\bar{d}_{1}$.

- $\mu_{d_{\mathrm{y}}}\left(d_{\mathrm{y}}\right)$ attains the (local) maximum at $d_{\mathrm{y}}=\bar{d}_{2}$.

From a mechanical point of view, $\bar{d}_{1}$ is characterized by the following conditions [4]:

- $d_{\mathrm{y}} \in\left(0, \bar{d}_{1}\right)$ implies $\mu_{d_{\mathrm{y}}}\left(d_{\mathrm{y}}\right)=u_{\max }^{(1)}>u_{\max }^{(2)}$.

- $d_{\mathrm{y}} \in\left(\bar{d}_{1},+\infty\right)$ implies $\mu_{d_{\mathrm{y}}}\left(d_{\mathrm{y}}\right)=u_{\max }^{(2)}>u_{\max }^{(1)}$. 
Namely, $u_{\max }^{(1)}=u_{\max }^{(2)}$ holds at the minimum point, $\bar{d}_{1}$, of $\mu_{d_{\mathrm{y}}}$. We also see that $\bar{d}_{2}$ and $\bar{d}_{3}$ are characterized by the following mechanical properties:

- $d_{\mathrm{y}} \in\left(0, \bar{d}_{2}\right)$ implies that the structure undergoes plastic deformation before the second impulse.

- $d_{\mathrm{y}} \in\left(\bar{d}_{2}, \bar{d}_{3}\right)$ implies that the structure undergoes plastic deformation only after the second impulse.

- $d_{\mathrm{y}} \in\left(\bar{d}_{3},+\infty\right)$ implies that the structure undergoes no plastic deformation.

Namely, $u_{\max }^{(1)}=d_{\mathrm{y}}$ holds at the local maximum point, $\bar{d}_{2}$, of $\mu_{d_{\mathrm{y}}}$, while $u_{\max }^{(2)}=d_{\mathrm{y}}$ holds at $\bar{d}_{3}$. Within the interval $\left[\bar{d}_{3},+\infty\right)$, the value of $\mu_{d_{\mathrm{y}}}$ does not change irrespective of the value of $d_{\mathrm{y}}$, because only elastic deformation takes place. If plastic deformation takes place before the second impulse and $u_{\max }^{(2)}>u_{\max }^{(1)}$ is satisfied, then $\mu_{d_{\mathrm{y}}}$ is strictly increasing with respect to $d_{\mathrm{y}}$. In other cases, $\mu_{d_{\mathrm{y}}}$ is decreasing or constant. For these two reasons, $\mu_{d_{\mathrm{y}}}$ has a local maximum point.

We are now in position to investigate the robustness function. Let $\tilde{d}_{\mathrm{y}}$ denote the nominal value of $d_{\mathrm{y}}$. Define the uncertainty set of $d_{\mathrm{y}}$ by

$$
\mathcal{D}(\alpha)=\left\{d_{\mathrm{y}} \in \mathbb{R}|| d_{\mathrm{y}}-\tilde{d}_{\mathrm{y}} \mid \leq \alpha, d_{\mathrm{y}}>0\right\} .
$$

The robustness function is defined by

$$
\hat{\alpha}_{d_{\mathrm{y}}}\left(u^{\mathrm{c}}\right)=\max \left\{\alpha \mid \max \left\{\mu_{d_{\mathrm{y}}}\left(d_{\mathrm{y}}\right) \mid d_{\mathrm{y}} \in \mathcal{D}(\alpha)\right\} \leq u^{\mathrm{c}}\right\},
$$

where $u^{\mathrm{c}}$ is the maximal allowable deformation.

For given $\alpha \geq 0$, define $\mu_{*}(\alpha)$ by

$$
\mu_{*}(\alpha)=\max \left\{\mu_{d_{\mathrm{y}}}\left(d_{\mathrm{y}}\right) \mid d_{\mathrm{y}} \in \mathcal{D}(\alpha)\right\} .
$$

By definition, the value of robustness function, $\hat{\alpha}_{d_{\mathrm{y}}}\left(u^{\mathrm{c}}\right)$, can be determined from the following condition:

$$
\mu_{*}\left(\hat{\alpha}_{d_{\mathrm{y}}}\left(u^{\mathrm{c}}\right)\right)=u^{\mathrm{c}}
$$

For notational simplicity, define $\bar{u}_{2}$ by

$$
\bar{u}_{2}=\mu_{d_{y}}\left(\bar{d}_{2}\right)=\frac{5}{2} \frac{v}{\omega} .
$$

By using the properties of $\mu_{d_{\mathrm{y}}}$ studied above, we can compute $\mu_{*}(\alpha)$ as follows.

- Case 1: $\tilde{d}_{\mathrm{y}} \in\left[\bar{d}_{2},+\infty\right)$.

- Case 1-a: $\alpha \in\left[0, \tilde{d}_{\mathrm{y}}-\bar{d}_{2}\right)$. It follows from $(26)$ that $\mathcal{D}(\alpha) \subseteq[v / \omega,+\infty)$. Hence, $\mu_{d_{\mathrm{y}}}$ is monotonically decreasing on $\mathcal{D}(\alpha)$, from which we obtain

$$
\mu_{*}(\alpha)=\mu_{d_{\mathrm{y}}}\left(\tilde{d}_{\mathrm{y}}-\alpha\right)
$$


- Case 1-b: $\alpha \in\left[\tilde{d}_{\mathrm{y}}-\bar{d}_{2}, \tilde{d}_{\mathrm{y}}\right)$. It follows from (26) that $\bar{d}_{2} \in \mathcal{D}(\alpha)$. On the other hand, on $\left(0, \bar{d}_{1}\right) \cap \mathcal{D}(\alpha)$ the function $\mu_{d_{\mathrm{y}}}$ attains the maximum at $\tilde{d}_{\mathrm{y}}-\alpha$. Therefore, we obtain

$$
\mu_{*}(\alpha)=\max \left\{\bar{u}_{2}, \mu_{d_{y}}\left(\tilde{d}_{\mathrm{y}}-\alpha\right)\right\} .
$$

- Case 1-c: $\alpha \in\left[\tilde{d}_{\mathrm{y}},+\infty\right)$. In this case, $(26) \operatorname{reads} \mathcal{D}(\alpha)=\left(0, \tilde{d}_{\mathrm{y}}+\alpha\right]$. Since $\mu_{d_{\mathrm{y}}}\left(d_{\mathrm{y}}\right) \rightarrow+\infty$ as $d_{\mathrm{y}} \rightarrow+0$, we obtain

$$
\mu_{*}(\alpha)=+\infty .
$$

- Case 2: $\tilde{d}_{\mathrm{y}} \in\left(0, \bar{d}_{2}\right)$.

- Case 2-a: $\alpha \in\left[0,-\tilde{d}_{\mathrm{y}}+\bar{d}_{2}\right)$ and $\alpha \in\left[0, \tilde{d}_{\mathrm{y}}\right)$. It follows from (26) that $\mathcal{D}(\alpha) \subseteq$ $\left(0, \bar{d}_{2}\right)$. Since $\mu_{d_{\mathrm{y}}}$ is convex on $\left(0, \bar{d}_{2}\right)$, the maximum of $\mu_{d_{\mathrm{y}}}$ on $\mathcal{D}(\alpha)$ is attained at an extreme point of $\mathcal{D}(\alpha)$. Namely, we obtain

$$
\mu_{*}(\alpha)=\max \left\{\mu_{d_{\mathrm{y}}}\left(\tilde{d}_{\mathrm{y}}-\alpha\right), \mu_{d_{\mathrm{y}}}\left(\tilde{d}_{\mathrm{y}}+\alpha\right)\right\} .
$$

- Case 2-b: $\alpha \in\left[-\tilde{d}_{\mathrm{y}}+\bar{d}_{2}, \tilde{d}_{\mathrm{y}}\right)$. This case arises only if $\tilde{d}_{\mathrm{y}}>\bar{d}_{2} / 2$. It follows from (26) that $\bar{d}_{2} \in \mathcal{D}(\alpha)$. On the other hand, on $\left(0, \bar{d}_{1}\right) \cap \mathcal{D}(\alpha)$ the function $\mu_{d_{y}}$ attains the maximum at $\tilde{d}_{\mathrm{y}}-\alpha$. Therefore, we obtain

$$
\mu_{*}(\alpha)=\max \left\{\bar{u}_{2}, \mu_{d_{y}}\left(\tilde{d}_{\mathrm{y}}-\alpha\right)\right\} .
$$

- Case 2-c: $\alpha \in\left[\tilde{d}_{\mathrm{y}},+\infty\right)$. In a manner similar to case 1-c, we obtain

$$
\mu_{*}(\alpha)=+\infty .
$$

In this way, the value of $\mu_{*}(\alpha)$ for a given $\alpha \geq 0$ can be obtained. Therefore, when $u^{\mathrm{c}}>0$ is given, we can find $\alpha_{*}$ satisfying $\mu_{*}\left(\alpha_{*}\right)=u^{\text {c }}$ with, e.g., the bisection method. Then, from (29), we conclude that $\hat{\alpha}_{d_{y}}\left(u^{\mathrm{c}}\right)=\alpha_{*}$.

Example 5. Consider cases (E), (F), and (G) in Table 1. The robustness curves of these three structures are collected in Figure 8. Cases (E) and (F) satisfy $\tilde{d}_{\mathrm{y}} \in\left(\bar{d}_{1}, \bar{d}_{2}\right)$, while case $(\mathrm{G})$ satisfies $\tilde{d}_{\mathrm{y}} \in\left(\bar{d}_{2}, \bar{d}_{3}\right)$. The robustness curve in Figure 8 (a) has a nonsmooth point. When $u^{\mathrm{c}}$ is large, the robustness function is determined by the constraint $u_{\max }^{(1)} \leq$ $u^{\mathrm{c}}$. At the nonsmooth point, we have that $u_{\max }^{(1)}=u_{\max }^{(2)}$. When $u^{\mathrm{c}}$ is smaller than the value at the nonsmooth point, the robustness function is determined by the constraint $u_{\max }^{(2)} \leq u^{\mathrm{c}}$. In Figure $8(\mathrm{~b})$, when $u^{\mathrm{c}}$ is large, the robustness function is determined by the constraint $u_{\max }^{(1)} \leq u^{\mathrm{c}}$. When $u^{\mathrm{c}}$ is decreased, the robustness function is determined by the local maximum of $\mu_{d_{\mathrm{y}}}$ in Figure 7 . At this point, $\hat{\alpha}_{d_{\mathrm{y}}}$ decreases discontinuously. For a smaller value of $u^{\mathrm{c}}$, the robustness function is determined by the constraint $u_{\max }^{(2)} \leq$ $u^{\mathrm{c}}$. Thus, as an important design implication, one can see that when the performance requirement is demanded to be improved, the critical deformation changes from $u_{\max }^{(1)}$ to $u_{\max }^{(2)}$, and at the transition point the robustness suddenly decreases. A similar situation can be observed in Figure 8(c). Namely, $u_{\max }^{(1)}>u_{\max }^{(2)}$ holds for a large value of $u^{\mathrm{c}}$, while 


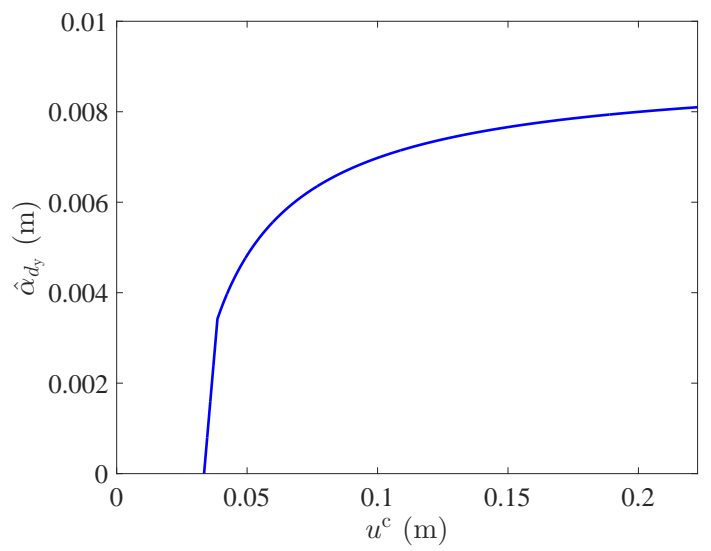

(a)

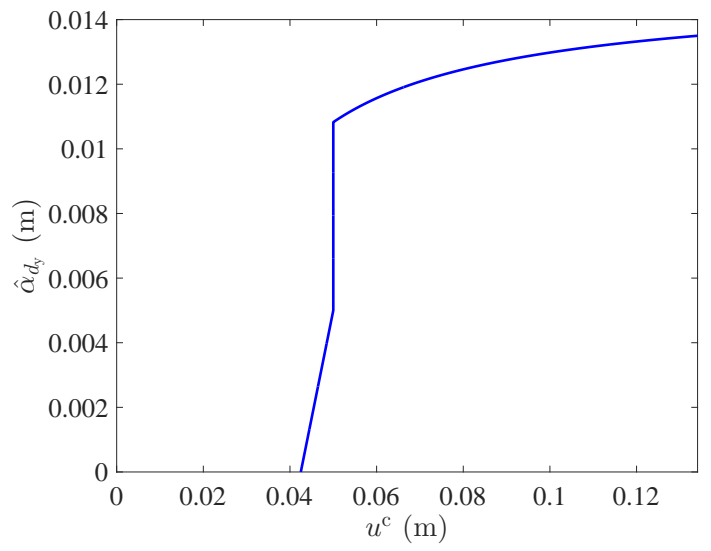

(b)

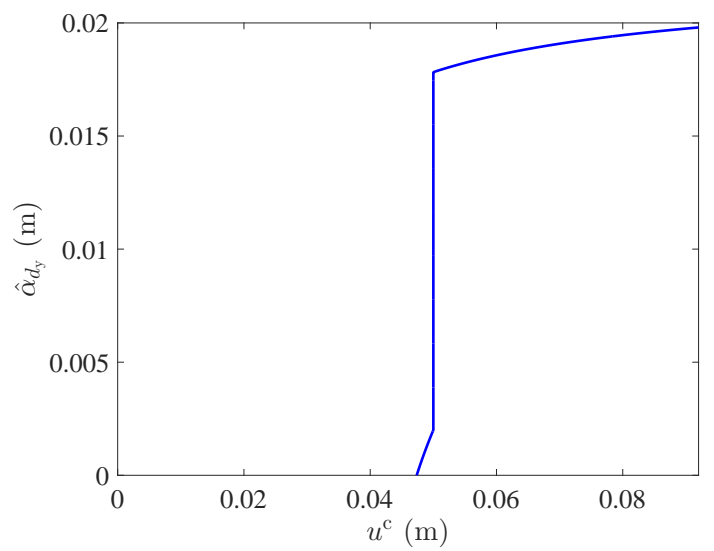

(c)

Figure 8: Robustness curves of three structures when uncertainty in the yield deformation is considered. (a) Case (E); (b) case (F); and (c) case (G). 
$u_{\max }^{(2)}>u_{\max }^{(1)}$ holds for a small value of $u^{\mathrm{c}}$. Therefore, the constraint $u_{\max }^{(2)} \leq u^{\mathrm{c}}$ is crucial when $u^{\mathrm{c}}$ is large, while $u_{\max }^{(1)} \leq u^{\mathrm{c}}$ is crucial when $u^{\mathrm{c}}$ is small. The point at which $\hat{\alpha}_{d_{y}}$ is discontinuous is the transition point of the crucial constraint. As a result, the robustness decreases discontinuously at the transition point. It is worth noting that, for a small value of $u^{\mathrm{c}}$ such that $u_{\max }^{(2)}>u_{\max }^{(1)}$ holds, case $(\mathrm{F})$ undergoes plastic deformation before the second impulse, while case $(\mathrm{G})$ undergoes plastic deformation only after the second impulse.

\section{Some properties of robustness measures}

In this section, we study some important properties of the robustness function considered in sections 4 and 5 .

The first three propositions show monotonicity properties of the robustness functions.

Proposition 6. Suppose that the assumptions in section 4 hold, i.e., $\omega$ and $d_{\mathrm{y}}$ are fixed and $v$ is uncertain. Then, the robustness function, defined by (10), satisfies

$$
\omega^{\prime}>\omega>0 \quad \Rightarrow \quad \hat{\alpha}_{v}\left(u^{\mathrm{c}} ; \tilde{v}, \omega^{\prime}, d_{\mathrm{y}}\right)>\hat{\alpha}_{v}\left(u^{\mathrm{c}} ; \tilde{v}, \omega, d_{\mathrm{y}}\right)
$$

for any $\tilde{v}>0$ and $d_{\mathrm{y}}>0$.

Proof. For any $\tilde{v}>0$ and $d_{\mathrm{y}}>0$, Proposition 1 (iii) shows that

$$
\omega^{\prime}>\omega>0 \quad \Rightarrow \quad \mu\left(v, \omega^{\prime}, d_{\mathrm{y}}\right)<\mu\left(v, \omega, d_{\mathrm{y}}\right) .
$$

This implies

$$
\max \left\{\alpha \mid \mu\left(\tilde{v}+\alpha, \omega^{\prime}, d_{\mathrm{y}}\right) \leq u^{\mathrm{c}}\right\}>\max \left\{\alpha \mid \mu\left(\tilde{v}+\alpha, \omega, d_{\mathrm{y}}\right) \leq u^{\mathrm{c}}\right\} .
$$

The assertion of the proposition follows from (12) and (39).

Proposition 6 implies that, when $v$ is uncertain, the robustness of a structure is always improved if we increase $\omega$.

Proposition 7. Suppose that the assumptions in section 5 hold, i.e., $v$ and $d_{\mathrm{y}}$ are fixed and $\omega$ is uncertain. Then, the robustness function, defined by (17), satisfies

$$
\tilde{\omega}^{\prime}>\tilde{\omega}>0 \quad \Rightarrow \quad \hat{\alpha}_{\omega}\left(u^{\mathrm{c}} ; v, \tilde{\omega}^{\prime}, d_{\mathrm{y}}\right)>\hat{\alpha}_{\omega}\left(u^{\mathrm{c}} ; v, \tilde{\omega}, d_{\mathrm{y}}\right)
$$

for any $v>0$ and $d_{\mathrm{y}}>0$.

Proof. In a manner similar to Proposition 6, this proposition follows from Proposition 1 (iii) and (19).

Proposition 7 implies that, when $\omega$ is uncertain, the robustness of a structure is always improved if we increase $\tilde{\omega}$.

Proposition 8. Suppose that the assumptions in section 5 hold, i.e., $v$ and $d_{\mathrm{y}}$ are fixed and $\omega$ is uncertain. Then, the robustness function, defined by (17), satisfies

$$
v^{\prime}>v>0 \quad \Rightarrow \quad \hat{\alpha}_{\omega}\left(u^{\mathrm{c}} ; v^{\prime}, \tilde{\omega}, d_{\mathrm{y}}\right)<\hat{\alpha}_{\omega}\left(u^{\mathrm{c}} ; v, \tilde{\omega}, d_{\mathrm{y}}\right)
$$

for any $\tilde{\omega}>0$ and $d_{\mathrm{y}}>0$. 
Proof. For any $\omega>0$ and $d_{\mathrm{y}}>0$, Proposition 1 (ii) shows that

$$
v^{\prime}>v>0 \quad \Rightarrow \quad \mu\left(v^{\prime}, \omega, d_{\mathrm{y}}\right)>\mu\left(v, \omega, d_{\mathrm{y}}\right) .
$$

This implies

$$
\max \left\{\alpha \mid \mu\left(v^{\prime}, \tilde{\omega}-\alpha, d_{\mathrm{y}}\right) \leq u^{\mathrm{c}}\right\}<\max \left\{\alpha \mid \mu\left(v, \tilde{\omega}-\alpha, d_{\mathrm{y}}\right) \leq u^{\mathrm{c}}\right\} .
$$

The assertion of the proposition follows from (19) and (43).

Proposition 8 implies that, when $\omega$ is uncertain, the robustness of a structure always decreases if we consider larger input $v$.

In the following, we study the relationship of robustness curves of two different structures. Attention is focused on crossing of robustness curves, illustrated in Example 2 and Example 3. We begin by establishing the relationship of graphs of $\mu_{v}$, defined by (8), of two different structures.

Lemma 9. Assume that $d_{\mathrm{y}}$ and $d_{\mathrm{y}}^{\prime}$ satisfy $0<d_{\mathrm{y}}<d_{\mathrm{y}}^{\prime}<(\sqrt{3}+1) d_{\mathrm{y}}$. Let $v(>0)$ and $s$ be the horizontal and vertical axes, respectively, and consider the graphs of $s=\mu_{v}\left(v ; \omega, d_{\mathrm{y}}\right)$ and $s=\mu_{v}\left(v ; \omega, d_{\mathrm{y}}^{\prime}\right)$. Then the two graphs are crossing just twice. Moreover, the values of $v$ at the intersection points, denoted $\bar{v}_{1}$ and $\bar{v}_{2}\left(\bar{v}_{1}<\bar{v}_{2}\right)$, are

$$
\begin{aligned}
& \bar{v}_{1}=\frac{1}{4} \omega\left(d_{\mathrm{y}}^{\prime}+\sqrt{12 d_{\mathrm{y}} d_{\mathrm{y}}^{\prime}-3\left(d_{\mathrm{y}}^{\prime}\right)^{2}}\right), \\
& \bar{v}_{2}=\omega\left(d_{\mathrm{y}}+\sqrt{3 d_{\mathrm{y}} d_{\mathrm{y}}^{\prime}}\right) .
\end{aligned}
$$

Proof. Define $\phi$ by

$$
\phi(v)=\mu_{v}\left(v ; \omega, d_{\mathrm{y}}\right)-\mu_{v}\left(v ; \omega, d_{\mathrm{y}}^{\prime}\right),
$$

which is explicitly written as

$$
\phi(v)= \begin{cases}0 & \text { if } v \in\left(0, \frac{1}{2} \omega d_{\mathrm{y}}\right), \\ 2 \frac{1}{\omega^{2} d_{\mathrm{y}}} v^{2}+\frac{1}{2} d_{\mathrm{y}}-2 \frac{1}{\omega} v & \text { if } v \in\left[\frac{1}{2} \omega d_{\mathrm{y}}, \frac{1}{2} \omega d_{\mathrm{y}}^{\prime}\right), \\ 2 \frac{1}{\omega^{2} d_{\mathrm{y}}} v^{2}+\frac{1}{2} d_{\mathrm{y}}-2 \frac{1}{\omega^{2} d_{\mathrm{y}}^{\prime}} v^{2}-\frac{1}{2} d_{\mathrm{y}}^{\prime} & \text { if } v \in\left[\frac{1}{2} \omega d_{\mathrm{y}}^{\prime}, \omega d_{\mathrm{y}}\right), \\ \frac{1}{\omega} v+\frac{3}{2} d_{\mathrm{y}}-2 \frac{1}{\omega^{2} d_{\mathrm{y}}^{\prime}} v^{2}-\frac{1}{2} d_{\mathrm{y}}^{\prime} & \text { if } v \in\left[\omega d_{\mathrm{y}}, \omega d_{\mathrm{y}}^{\prime}\right), \\ \frac{1}{\omega} v+\frac{3}{2} d_{\mathrm{y}}-\frac{1}{\omega} v-\frac{3}{2} d_{\mathrm{y}}^{\prime} & \text { if } v \in\left[\omega d_{\mathrm{y}}^{\prime},(\sqrt{3}+1) \omega d_{\mathrm{y}}\right), \\ \frac{1}{2} \frac{1}{\omega^{2} d_{\mathrm{y}}} v^{2}+\frac{1}{2} d_{\mathrm{y}}-\frac{1}{\omega} v-\frac{3}{2} d_{\mathrm{y}}^{\prime} & \text { if } v \in\left[(\sqrt{3}+1) \omega d_{\mathrm{y}},(\sqrt{3}+1) \omega d_{\mathrm{y}}^{\prime}\right), \\ \frac{1}{2} \frac{1}{\omega^{2} d_{\mathrm{y}}} v^{2}+\frac{1}{2} d_{\mathrm{y}}-\frac{1}{2} \frac{1}{\omega^{2} d_{\mathrm{y}}^{\prime}} v^{2}-\frac{1}{2} d_{\mathrm{y}}^{\prime} & \text { if } v \in\left[(\sqrt{3}+1) \omega d_{\mathrm{y}}^{\prime},+\infty\right) .\end{cases}
$$

By computing $\frac{\mathrm{d} \phi}{\mathrm{d} v}(v)$, we easily see that

$$
\phi(v)= \begin{cases}\text { (constant) } & \text { if } v \in\left(0, \frac{1}{2} \omega d_{\mathrm{y}}\right), \\ \text { (strict. incrg. }) & \text { if } v \in\left(\frac{1}{2} \omega d_{\mathrm{y}}, \omega d_{\mathrm{y}}\right), \\ \text { (strict. dcrg. }) & \text { if } v \in\left(\omega d_{\mathrm{y}}, \omega d_{\mathrm{y}}^{\prime}\right), \\ \text { (constant) } & \text { if } v \in\left(\omega d_{\mathrm{y}}^{\prime},(\sqrt{3}+1) \omega d_{\mathrm{y}}\right), \\ \text { (strict. incrg. }) & \text { if } v \in\left((\sqrt{3}+1) \omega d_{\mathrm{y}},+\infty\right),\end{cases}
$$


where "strict. incrg." and "strict. dcrg." mean "strictly monotonically increasing" and "strictly monotonically decreasing," respectively.

It follows from $\phi(0)=0$ and (48) that we obtain

$$
\phi\left(\omega d_{\mathrm{y}}\right)>0 .
$$

From (47), we obtain

$$
\phi\left(\omega d_{\mathrm{y}}^{\prime}\right)=\frac{3}{2}\left(d-d_{\mathrm{y}}^{\prime}\right)<0 .
$$

It follows from (49) and (50) that there exists a unique $v \in\left(\omega d_{\mathrm{y}}, \omega d_{\mathrm{y}}^{\prime}\right)$ satisfying $\phi(v)=0$. This means that the two graphs of interest have a unique intersection point in this interval. By solving

$$
\frac{1}{\omega} v+\frac{3}{2} d_{\mathrm{y}}=2 \frac{1}{\omega^{2} d_{\mathrm{y}}^{\prime}} v^{2}+\frac{1}{2} d_{\mathrm{y}}^{\prime}
$$

with respect to $v$, we can find that this intersection point is located at $v=\bar{v}_{1}$.

Next, it follows from (48) and (50) that we obtain

$$
\phi\left((\sqrt{3}+1) \omega d_{\mathrm{y}}\right)<0 .
$$

From (47), we obtain

$$
\phi\left((\sqrt{3}+1) \omega d_{\mathrm{y}}^{\prime}\right)=\frac{1}{2 d_{\mathrm{y}}}\left[(4+2 \sqrt{3}) d_{\mathrm{y}}^{\prime}-d_{\mathrm{y}}\right]\left(d_{\mathrm{y}}^{\prime}-d_{\mathrm{y}}\right)>0
$$

It follows from $(52)$ and $(53)$ that there exists a unique $v \in\left((\sqrt{3}+1) \omega d_{\mathrm{y}},(\sqrt{3}+1) \omega d_{\mathrm{y}}^{\prime}\right)$ satisfying $\phi(v)=0$. Namely, the two graphs have a unique intersection point in this interval. By solving

$$
\frac{1}{2} \frac{1}{\omega^{2} d_{\mathrm{y}}} v^{2}+\frac{1}{2} d_{\mathrm{y}}=\frac{1}{\omega} v+\frac{3}{2} d_{\mathrm{y}}^{\prime}
$$

with respect to $v$, we can find that this intersection point is located at $v=\bar{v}_{2}$.

We can now show (double) crossing of the two robustness curves presented in Example 2 .

Proposition 10. Suppose that the assumptions in section 4 hold, i.e., $\omega$ and $d_{\mathrm{y}}$ are fixed and $v$ is uncertain. Assume that $d_{\mathrm{y}}$ and $d_{\mathrm{y}}^{\prime}$ satisfy $0<d_{\mathrm{y}}<d_{\mathrm{y}}^{\prime}<(\sqrt{3}+1) d_{\mathrm{y}}$. Then, for any $\tilde{v}>0$ and $\omega>0$, the number of crossing points of the two robustness curves, $s=\hat{\alpha}_{v}\left(u^{\mathrm{c}} ; \tilde{v}, \omega, d_{\mathrm{y}}\right)$ and $s=\hat{\alpha}_{v}\left(u^{\mathrm{c}} ; \tilde{v}, \omega, d_{\mathrm{y}}^{\prime}\right)$, is given as follows:

- If $\tilde{v} \in\left(0, \bar{v}_{1}\right)$, then the two curves are crossing twice.

- If $\tilde{v} \in\left[\bar{v}_{1}, \bar{v}_{2}\right)$, then the two curves are crossing once.

- If $\tilde{v} \in\left[\bar{v}_{2},+\infty\right)$, then the two curves are not crossing.

Proof. The assertion follows from Lemma 9 and (14). 
In the case of Example 2, put $\omega=10.0, d_{\mathrm{y}}=0.03$, and $d_{\mathrm{y}}^{\prime}=0.04$ to obtain $\bar{v}_{1}=0.345$. Thus, $v=0.225 \in\left(0, \bar{v}_{1}\right)$ holds, and thence Figure 4 that shows two intersection points of the robustness curves agrees with Proposition 10.

It follows from Proposition 10 that, if $v$ is uncertain and $0<\tilde{v}<\bar{v}_{2}$, we obtain

$$
d_{\mathrm{y}}^{\prime}>d_{\mathrm{y}}>0 \quad \nRightarrow \quad \hat{\alpha}_{v}\left(u^{\mathrm{c}} ; \tilde{v}, \omega, d_{\mathrm{y}}^{\prime}\right)>\hat{\alpha}_{v}\left(u^{\mathrm{c}} ; \tilde{v}, \omega, d_{\mathrm{y}}\right)
$$

Namely, robustness is not necessarily increased by increasing $d_{\mathrm{y}}$. The assumption made in Proposition 10 is not a strict one, and hence crossing of robustness curves often occurs.

With reference to $\bar{v}_{1}$ and $\bar{v}_{2}$ in (44) and (45), define $\bar{\omega}_{1}$ and $\bar{\omega}_{2}$ by

$$
\begin{aligned}
& \bar{\omega}_{1}=\frac{4 v}{d_{\mathrm{y}}^{\prime}+\sqrt{12 d_{\mathrm{y}} d_{\mathrm{y}}^{\prime}-3\left(d_{\mathrm{y}}^{\prime}\right)^{2}}}, \\
& \bar{\omega}_{2}=\frac{v}{d_{\mathrm{y}}+\sqrt{3 d_{\mathrm{y}} d_{\mathrm{y}}^{\prime}}},
\end{aligned}
$$

where $\bar{\omega}_{1}>\bar{\omega}_{2}$. Crossing of the robustness curves in Example 3 can be explained as follows.

Proposition 11. Suppose that the assumptions in section 5 hold, i.e., $v$ and $d_{\mathrm{y}}$ are fixed and $\omega$ is uncertain. Assume that $d_{\mathrm{y}}$ and $d_{\mathrm{y}}^{\prime}$ satisfy $0<d_{\mathrm{y}}<d_{\mathrm{y}}^{\prime}<(\sqrt{3}+1) d_{\mathrm{y}}$. Then, for any $v>0$ and $\tilde{\omega}>0$, the number of crossing points of the two robustness curves, $s=\hat{\alpha}_{\omega}\left(u^{\mathrm{c}} ; v, \tilde{\omega}, d_{\mathrm{y}}\right)$ and $s=\hat{\alpha}_{\omega}\left(u^{\mathrm{c}} ; v, \tilde{\omega}, d_{\mathrm{y}}^{\prime}\right)$, is given as follows:

- If $\tilde{\omega} \in\left(\bar{\omega}_{1},+\infty\right)$, then the two curves are crossing twice.

- If $\tilde{\omega} \in\left(\bar{\omega}_{2}, \bar{\omega}_{1}\right]$, then the two curves are crossing once.

- If $\tilde{\omega} \in\left(0, \bar{\omega}_{2}\right]$, then the two curves are not crossing.

Proof. It follows from Lemma 9, (56), and (57) that $\omega=\bar{\omega}_{1}$ and $\omega=\bar{\omega}_{2}$ are two intersection points of the graphs $s=\mu_{\omega}\left(\omega ; v, d_{\mathrm{y}}\right)$ and $s=\mu_{\omega}\left(\omega ; v, d_{\mathrm{y}}^{\prime}\right)$. Therefore, the assertion of this proposition follows from (21).

In the case of Example 3, we have $v=0.2, d_{\mathrm{y}}=0.03$, and $d_{\mathrm{y}}^{\prime}=0.04$, which yield $\bar{\omega}_{1}=5.798$ and $\tilde{\omega}=8.0 \in\left(\bar{\omega}_{1},+\infty\right)$. Therefore, Figure 6 showing two intersection points of the robustness curves agrees with Proposition 11.

A design implication of Proposition 11 is that, when $\omega$ is uncertain and $\tilde{\omega}<\bar{\omega}_{2}$, we have that

$$
d_{\mathrm{y}}^{\prime}>d_{\mathrm{y}}>0 \quad \nRightarrow \quad \hat{\alpha}_{\omega}\left(u^{\mathrm{c}} ; v, \tilde{\omega}, d_{\mathrm{y}}^{\prime}\right)>\hat{\alpha}_{\omega}\left(u^{\mathrm{c}} ; v, \tilde{\omega}, d_{\mathrm{y}}\right)
$$

Namely, increase of $d_{\mathrm{y}}$ does not necessarily yield improvement of robustness.

\section{Conclusions}

In this paper, we have presented a robustness assessment method for elastoplastic single-degree-of-freedom structures subjected to double impulse input. Based on the infogap theory [12], a quantitative measure of robustness, called the robustness function, has 
been defined. The closed-form expression of the critical elastoplastic response [4] plays a key role in evaluation of the robustness measure of a structure.

Fundamental properties of the structural robustness have been derived by using the closed-form expression of the critical response. When the initial velocity of the input, $v$, is uncertain, robustness of a structure is always improved if its natural frequency is increased. Also, when the natural circular frequency of a structure, $\omega$, is uncertain, robustness is always improved if the nominal value of $\omega$ is increased. In contrast, when $v$ or $\omega$ is uncertain, robustness is not necessarily improved even if the yield deformation of the structure, $d_{\mathrm{y}}$, is increased. Moreover, the robustness preference between two structural designs with different values of $d_{\mathrm{y}}$ can possibly reverse, when the designer's performance requirement changes. We have derived a sufficient condition for occurrence of this reversal. When $d_{\mathrm{y}}$ is uncertain, robustness of a structure can possibly decreases drastically, actually in a discontinuous manner, when the performance requirement, $u^{\mathrm{c}}$, is demanded to be improved. This is because the deformation before the second impulse is critical for a large value of $u^{c}$, while the deformation after the second impulse becomes critical for a small value of $u^{\mathrm{c}}$.

Extensions of the presented approach to the structural response against the triple impulse [8] and the multiple impulse [9] remain to be studied. Propagation of uncertainty to non-critical structural response could be explored. Also, we could explore an extension to the situation that an estimated probability density function for a parameter is available but is erroneous to some unknown extent. Given the magnitude of uncertainty, a problem for finding the set of structural designs satisfying the constraints under uncertainty could be considered.

Acknowledgments. The work of the first author is partially supported by JSPS KAKENHI (C) 26420545.

\section{References}

[1] Kalkan, E., Kunnath, S.K.: Effects of fling step and forward directivity on seismic response of buildings. Earthquake Spectra, 22, 367-390 (2006).

[2] Mavroeidis, G.P., Papageorgiou, A.S.: A mathematical representation of near-fault ground motions. Bulletin of the Seismological Society of America, 93, 1099-1131 (2003).

[3] Takewaki, I., Moustafa, A., Fujita, K: Improving the Earthquake Resilience of Buildings: The Worst Case Approach. Springer-Verlag, London (2013).

[4] Kojima, K., Takewaki, I.: Critical earthquake response of elastic-plastic structures under nearfault ground motions (Part 1: Fling-step input). Frontiers in Built Environment (Specialty Section: Earthquake Engineering), 1, Article No. 12 (2015).

[5] Kojima, K., Takewaki, I.: Closed-form critical earthquake response of elastic-plastic structures on compliant ground under near-fault ground motions. Frontiers in Built Environment (Specialty Section: Earthquake Engineering), 2, Article No. 1 (2016).

[6] Kojima, K., Takewaki, I.: Closed-form dynamic stability criterion for elastic-plastic structures under near-fault ground motions. Frontiers in Built Environment (Specialty Section: Earthquake Engineering), 2, Article No. 6 (2016).

[7] Nabeshima, K., Taniguchi, R., Kojima, K., Takewaki, I.: Closed-form overturning limit of rigid block under critical near-fault ground motions. Frontiers in Built Environment (Specialty Section: Earthquake Engineering), 2, Article No. 9 (2016).

[8] Kojima, K., Takewaki, I.: Critical earthquake response of elastic-plastic structures under near-fault ground motions (Part 2: Forward-directivity input). Frontiers in Built Environment (Specialty Section: Earthquake Engineering), 1, Article No. 13 (2015). 
[9] Kojima, K., Takewaki, I.: Critical input and response of elastic-plastic structures under longduration earthquake ground motions. Frontiers in Built Environment (Specialty Section: Earthquake Engineering), 1, Article No. 15 (2015).

[10] Clough, R.W., Penzien, J.: Dynamics of Structures (2nd ed.). McGraw-Hill, New York (1993).

[11] Chopra, A.K.: Dynamics of Structures: Theory and Applications to Earthquake Engineering (4th ed.). Prentice Hall, Upper Saddle River (2012).

[12] Ben-Haim, Y.: Information-gap Decision Theory: Decisions under Severe Uncertainty (2nd ed.). Academic Press, London (2006).

[13] Hot, A., Cogan, S., Foltête, E., Kerschen, G., Buffe, F., Buffe, J., Behar, S.: Design of uncertain prestressed space structures: an info-gap approach. In: Simmermacher, T., Cogan, S., Horta, L.G., Barthorpe, R. (eds.), Topics in Model Validation and Uncertainty Quantification, Vol. 4, Springer, New York, pp. 13-20 (2012).

[14] Kanno, Y., Ben-Haim, Y.: Redundancy and robustness, or, when is redundancy redundant? Journal of Structural Engineering (ASCE), 137, 935-945 (2011).

[15] Kanno, Y., Takewaki, I.: Sequential semidefinite program for maximum robustness design of structures under load uncertainties. Journal of Optimization Theory and Applications, 130, 265-287 (2006).

[16] Kanno, Y., Takewaki, I.: Robustness analysis of trusses with separable load and structural uncertainties. International Journal of Solids and Structures, 43, 2646-2669 (2006).

[17] Matsuda, Y., Kanno, Y.: Robustness analysis of structures based on plastic limit analysis with uncertain loads. Journal of Mechanics of Materials and Structures, 3, 213-242 (2008).

[18] Takewaki, I., Ben-Haim, Y.: Info-gap robust design with load and model uncertainties. Journal of Sound and Vibration, 288, 551-570 (2005).

[19] Vinot, P., Cogan, S., Cipolla, V.: A robust model-based test planning procedure. Journal of Sound and Vibration, 288, 571-585 (2005).

[20] Wu, D., Gao, W., Li, G., Tangaramvong, S., Tin-Loi, F.: Robust assessment of collapse resistance of structures under uncertain loads based on info-gap model. Computer Methods in Applied Mechanics and Engineering, 285, 208-227 (2015).

[21] Au, S.-K.: Critical excitation of sdof elasto-plastic systems. Journal of Sound and Vibration, 296, $714-733$ (2006).

[22] Au, S.-K.: First passage probability of elasto-plastic systems by importance sampling with adapted process. Probabilistic Engineering Mechanics, 23, 114-124 (2008).

[23] Au, S.-K.: Importance sampling for elasto-plastic systems using adapted process with deterministic control. International Journal of Non-Linear Mechanics, 44, 190-199 (2009).

[24] Au, S.-K., Lam, H.-F., Ng, C.-T.: Reliability analysis of single-degree-of-freedom elastoplastic systems. I: Critical excitations. Journal of Engineering Mechanics (ASCE), 133, 1072-1080 (2007).

[25] Moustafa, A., Ueno, K., Takewaki, I.: Critical earthquake loads for SDOF inelastic structures considering evolution of seismic waves. Earthquakes and Structures, 1, 147-162 (2010).

[26] Abbas, A.M.: Critical seismic load inputs for simple inelastic structures. Journal of Sound and Vibration, 296, 949-967 (2006).

[27] Kanno, Y., Takewaki, I.: Semidefinite programming for dynamic steady-state analysis of structures under uncertain harmonic loads. Computer Methods in Applied Mechanics and Engineering, 198, 3239-3261 (2009).

[28] Drenick, R.F.: Model-free design of aseismic structures. Journal of Engineering Mechanics Division (ASCE), 96, 483-493 (1970).

[29] Abbas, A.M., Manohar, C.S.: Investigations into critical earthquake load models within deterministic and probabilistic frameworks. Earthquake Engineering and Structural Dynamics, 31, 813-832 (2002).

[30] Takewaki, I.: Critical Excitation Methods in Earthquake Engineering (2nd ed.). ButterworthHeinemann, Oxford (2013). 